\title{
Primary malignant fibrous histiocytoma of the kidney: report of a case and literature review
}

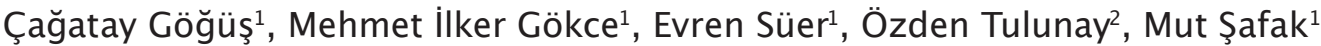

${ }^{1}$ Department of Urology, Faculty of Medicine, Ankara University, Ankara, Turkey

2Department of Pathology, Faculty of Medicine, Ankara University, Ankara, Turkey

Submitted:

11.01 .2013

Accepted:

25.01.2013

Correspondence:

Mehmet ilker Gökce

Department of Urology, Faculty of Medicine, Ankara University, Sihhıye 06590 Ankara, Turkey Phone: +90 3125082258

E-mail: migokce@yahoo.com

(C) Copyright 2013 by Turkish Association of Urology

Available online at www.turkishjournalofurology.com

\begin{abstract}
We report a 44-year-old woman with a malignant fibrous histiocytoma (MFH) of the kidney. Primary renal MFH is an extremely rare tumor with a poor prognosis. Renal MFH is differentiated from renal cell carcinoma, renal sarcoma, and sarcomatoid renal tumors only by histological and immunohistochemical studies. Because the therapeutic options for MFH are different, its early diagnosis is imperative.
\end{abstract}

Key words: Immunohistochemistry; malignant fibrous histiocytoma; renal cell cancer.

\section{Introduction}

Renal sarcoma is uncommon and constitutes only $1 \%$ to $3 \%$ of all malignant renal tumors. Malignant fibrous histiocytoma (MFH) is an unusual type of renal sarcoma and is believed to arise from primitive mesenchymal cells that demonstrate both histiocytic and fibroblastic differentiation. Retroperitoneal primary $\mathrm{MFH}$ with renal involvement is not uncommon, but renal $\mathrm{MFH}$ is rare; approximately 55 cases have been reported in the literature. ${ }^{[1]}$

We present a new case of renal MFH diagnosed using a wide range of immunohistochemical studies.

\section{Case presentation}

A 44-year-old woman presented with a 6-month history of left flank pain and abdominal discomfort. A physical examination confirmed the presence of a large mass in the left hypochondrium. Laboratory tests showed an elevated sedimentation rate and anemia, but chest X-rays were normal. Ultrasonographic imaging revealed a $12 \times 10 \times 10 \mathrm{~cm}$ solid tumor spreading into perirenal fat in the lower-mid portion of the left kidney. Computer tomography (CT) confirmed the tumor with suspected invasion of the sigmoid colon. However, no distant organ metastases were found.
The patient underwent left radical nephrectomy by a transperitoneal approach. Partial left colon resection was also performed, with a tumor-free surgical margin on frozen sections. Three courses of polychemotherapy with Adriblastina, Holoxan, Uromitexan, and radiotherapy were performed. However, she died as a result of the disease within the first postoperative year. Informed consent was obtained from the patient regarding sharing her clinical data for scientific purposes.

\section{Pathological features}

The kidney had a nodular surface and demonstrated a hemorrhagic tissue defect. Kidney tissue sections demonstrated that tumor had replaced $14 \times 14 \times 9 \mathrm{~cm}$ of the renal tissue.

Although CT appeared to demonstrate that the tumor involved the mesentery of the sigmoid colon, the resected left colon segment was free of tumor. Mesenteric lymph nodes dissected from the colon demonstrated reactive changes.

Five months after hospital discharge, the patient was readmitted with tumor recurrence and omental metastases. A jejunal lesion was documented by ultrasound, and multiple metastases were observed within the mesenteric tissues. Eight months after the initial operation, a left omental resection was performed, and the omental tissues were observed 


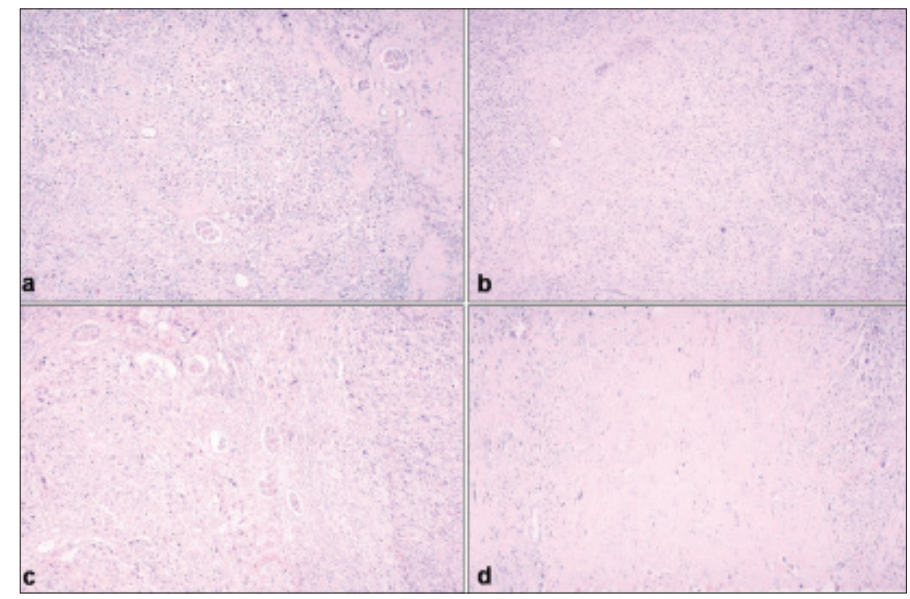

Figure 1. The renal parenchyma is widely occupied by a pleomorphic sarcomatous tumor composed of elongated spindle cells with marked pleomorphism and multinucleated pleomorphic giant cells $(\mathrm{a}-\mathrm{c})(\times 10, \times 10, \times 10)$. Tumor embedded in collagenous stroma, leaving only scattered cells within a large collagenous background $(\times 10)$

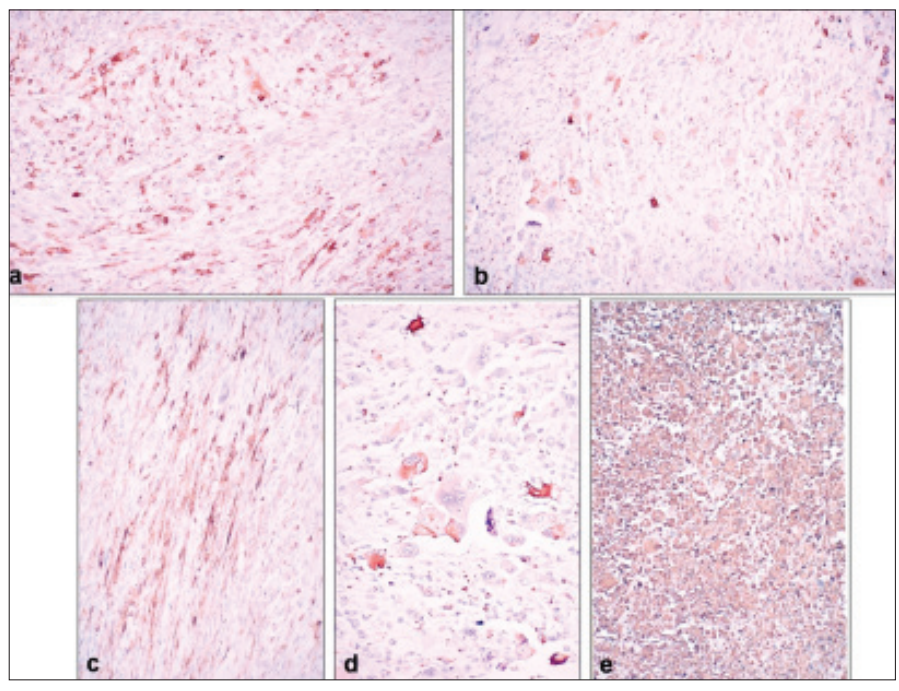

Figure 3. Immunohistochemistry of the tumor, Peroxidase. CD68 expression in spindle and histiocytic cells $(\mathrm{a}, \mathrm{c})(\times 25$, $\times 25)$ and giant cells $(\mathrm{b}, \mathrm{d})(\times 25, \times 50)$. Strong and diffuse vimentin positivity $(\mathrm{e})(\times 25)$

to be widely occupied by a tumor with histology similar to the primary tumor.

Histologically, the kidney was widely occupied by a pleomorphic sarcomatous tumor. Microscopic examination showed that the tumor was composed of elongated spindle cells displaying a patchy and a faint storiform pattern. Spindle-shaped fibroblastic cells were embedded in collagenous stroma and were extensive in some areas, leaving only scattered cells within a large, sometimes necrotic, collagenous background (Figure 1). Groups of

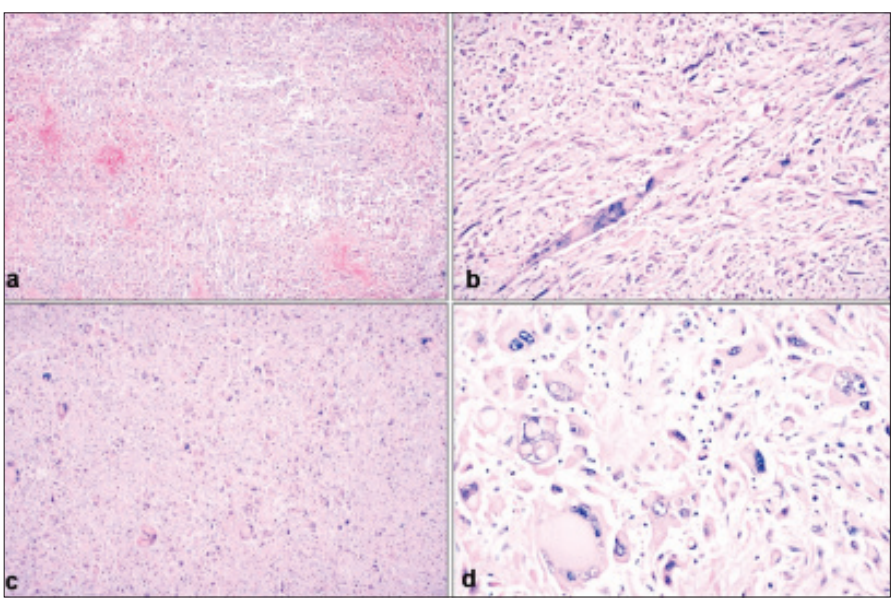

Figure 2. Histology of the tumor, HE. Spindle and histiocytic cells (a), including multinucleated pleomorphic giant cells with bizarre nuclei $(c)(\times 10, \times 25)$. Elongated plump spindle cells arranged in short fascicles displaying a patchy and faint storiform pattern invading the renal tissue $(b)(\times 50)$. Areas with a high degree of cellular pleomorphism composed of rounded, polygonal, and irregularly shaped histiocyte-like cells, often with very bizarre multinucleated giant cells with abundant eosinophilic cytoplasm $(d)(\times 100)$

histiocytes, inflammatory cell infiltration, and highly pleomorphic bizarre giant cells, some osteoclast-like, with large nuclei and a high mitotic index, were interspersed (Figure 2). Tumor cells penetrated the capsule into the perinephric fat.

\section{Immunohistochemistry}

Immunohistochemical (IHC) analysis of the tumor was performed, as shown in Table 1. The primary tumor cells were diffusely positive for CD10, vimentin (VIM) and CD68 (Figure 3). Stains for $\alpha 1$-antitrypsin and $\alpha 1$-antichymotrypsin were strongly and moderately positive, respectively, in the tumor cells, but stains for pan cytokeratin (pan CK), epithelial membrane antigen (EMA), smooth-muscle actin (SMA), S-100 protein (S-100) and desmin were negative. Additional IHC analyses were performed for the metastatic intestinal and omental lesions, and they demonstrated that those tumors were also negative for panCK, EMA, SMA, S100, desmin, NSE, CD34, HMB45, and C-Kit and were strongly positive for VIM and CD68. The histological and IHC features were those of an $\mathrm{MFH}$, and the histopathological diagnosis was storiform-pleomorphic $\mathrm{MFH}$ arising from the kidney.

\section{Discussion}

Primary sarcomas of the kidney are rare, accounting for only $1 \%$ to $3 \%$ of malignant renal tumors. ${ }^{[2]}$ Approximately $12 \%$ to $14 \%$ of MFHs occur in the retroperitoneum or kidneys. Retroperitoneal $\mathrm{MFH}$ may also involve the kidney by local 
Table 1. Details and the results of the antibody panel

\begin{tabular}{|c|c|c|c|}
\hline ANTIBODY & Source & Dilution & Reactivity \\
\hline Pan cytokeratin (panCK) ${ }^{\mathrm{a}}$ & Novocastra & $1: 50$ & - \\
\hline $\mathrm{CD} 10^{\mathrm{b}}$ & Novocastra & 1:50 & + \\
\hline Epithelial membrane antigen (EMA) ${ }^{\mathrm{d}}$ & Novocastra & $1: 300$ & - \\
\hline Vimentin (VIM) ${ }^{\mathrm{b}}$ & Neomarkers & $1: 200$ & + \\
\hline Smooth-muscle actin (SMA) ${ }^{d}$ & Neomarkers & $1: 300$ & - \\
\hline Desmin $^{\mathrm{a}}$ & Novocastra & $1: 50$ & - \\
\hline Myoglobin ${ }^{\mathrm{a}}$ & Immunon & $1: 600$ & - \\
\hline S-100 protein $(S-100)^{a}$ & Zymed & $1: 50$ & - \\
\hline $\mathrm{NSE}^{\mathrm{d}}$ & Neomarkers & $1: 25$ & - \\
\hline $\mathrm{CD}^{\mathrm{a}}$ & Dako & $1: 75$ & + \\
\hline $\mathrm{HMB}^{\mathrm{d}} 5^{\mathrm{d}}$ & Dako & $1: 50$ & - \\
\hline CD34 ${ }^{\mathrm{b}}$ & Neomarkers & $1: 30$ & - \\
\hline $\mathrm{C}-\mathrm{kit}^{\mathrm{c}}$ & Novocastra & $1: 50$ & - \\
\hline \multicolumn{4}{|c|}{ asections were preheated with $0.1 \%$ trypsin for 3 min at $37^{\circ} \mathrm{C}$. } \\
\hline \multicolumn{4}{|c|}{ SSections were preheated in a conventional pressure cooker for 90 seconds in a citrate buffer solution } \\
\hline \multicolumn{4}{|c|}{ Sections were preheated in a conventional pressure cooker for 90 seconds in an EDTA solution } \\
\hline ¿No pretreatment was performed & & & \\
\hline
\end{tabular}

extension. ${ }^{[1]}$ The mainstay of treatment is surgery, and adjuvant chemotherapy has also been suggested to improve survival.$^{[3]}$ MFHs arising from the renal parenchyma or renal capsule represent less than $6 \%$ of renal sarcomas. ${ }^{[4-11]}$ The most frequent presenting symptoms are a palpable abdominal mass, fever, fatigue, weight loss, and gastrointestinal problems. ${ }^{[12]}$ These symptoms are non-specific and usually appear late. Therefore, early diagnosis is difficult. A correct preoperative diagnosis was not made in any of the reports in the literature. Symptoms, a physical examination, and imaging are not sufficient for the clinical diagnosis of renal $\mathrm{MFH}$, and the diagnosis can only be made histopathologically. The tumor is thought to arise from the system of Gerota's fascia/renal capsule and must be differentiated from other more frequent renal cell carcinomas because it has a poor prognosis and requires additional treatment. Primary renal MFH is a tumor of the middle aged and elderly, with equal sex distribution, and most likely due to the small sample size, a predilection for the left kidney. ${ }^{[13]}$ The symptoms appear late and are non-specific; therefore, early diagnosis is difficult. ${ }^{[14]} \mathrm{In}$ most cases, MFH presents with less parenchymal involvement in imaging studies and more frequently with normal urine compared to renal cell carcinoma. ${ }^{[15]}$

Malignant fibrous histiocytoma must be differentiated from other sarcomas, sarcomatoid carcinoma, and renal cell carcinoma. ${ }^{[13,16,17]}$ Because most renal MFHs arise from the capsule, intracavitary progression and consecutive hematuria are rare. ${ }^{[13,18,19]}$ Symptoms, a physical examination, and imaging are insufficient for differentiating MFH from other renal tumors, and histopathology is essential for its differentiation. ${ }^{[18-21]} \mathrm{MFH}$ is a common type of soft tissue sarcoma that was initially described four decades ago, and it has been shown to have the characteristics of both mesenchymal cells and mononuclear phagocytes ${ }^{[22-24]}$ The most common renal sarcomas are characterized by typical immunophenotypes that include negativity for $\mathrm{CD} 68{ }^{[20]} \mathrm{MFH}$ is also positive for vimentin and $\alpha 1$-antitrypsin, but these are less specific. Unlike sarcomatoid carcinoma, MFH lacks immunoreactivity for epithelial markers. ${ }^{[13,25]}$

The treatment of MFH is radical surgery. The role of adjuvant radiotherapy is questionable and offers little, if any, benefit. ${ }^{[14,18,19,21]}$ Only early radical surgery and postoperative polychemotherapy can achieve success. ${ }^{[13,20]}$ If local infiltration or distant metastases are present, treatment with polychemotherapy may be indicated, although the effectiveness is questionable and the response rate is only $33 \%{ }^{[26]}$ The overall prognosis is poor, and the 5-year survival rate is less than $14 \%$. $^{[12]}$ The present case demonstrated recurrence and metastases postoperatively within five and eight months, respectively, and despite polychemotherapy, the patient died of disease within the first postoperative year. 
Informed Consent: Written informed consent was obtained from patients who participated in this case.

Peer-review: Externally peer-reviewed.

Author Contributions: Concept - Ç.G., M.Ş.; Design - M.İ.G., E.S., Ö.T.; Supervision - Ç.G., M.Ş.; Funding - M.İ.G., E.S.; Materials M.İ.G., E.S., Ö.T.; Data Collection and/or Processing - M.İ.G., E.S., Ö.T.; Analysis and/or Interpretation - Ç.G., E.S., Ö.T.; Literature Review - M.İ.G., E.S., Ö.T.

Conflict of Interest: No conflict of interest was declared by the authors.

Financial Disclosure: The authors declared that this study has received no financial support.

\section{References}

1. Weiss SW, Enzinger FM. Malignant fibrous histiocytoma, An analysis of 200 cases. Cancer 1978;41:2250-66.

2. Farrow GM, Harrison EG, Utz DC. Sarcomas and sarcomatoid and mixed malignant tumors of the kidney in adults. Cancer 1968;22:556-63.

3. Virgili G, Di Stasi SM, Storti L, Orlandi A, Vespasiani G. Successful management of retroperitoneal malignant fibrous histiocytoma involving both kidneys. Scand J Urol Nephrol 2000;34:208-10.

4. Tarjan M, Cserni G, Szabo Z. Malignant fibrous histiocytoma of the kidney. Scand J Urol Nephrol 2001;35:518-20.

5. Takahashi S, Tsukamoto T, Lieber M. Genitourinary sarcomas in adults, In: Vogelzang NJ, ed. Comprehensive Textbook of Oncology. St Louis; Williams and Wilkins, 1992;1124-39.

6. Shilkhoda A, Lewis E. Renal sarcoma and sarcomatoid renal cell carcinoma: CT and angiographic features. Radiology 1987;162:353-7.

7. Sing SK, Mandal AK, Agarwal MM, Das A. Primary renal inflammatory malignant fibrous hisitocytoma: a diagnostic challenge. Int J Urol 2006;13:1000-2.

8. Joseph TJ, Becker DI, Turton AF. Renal malignant fibrous histiocytoma. Urology 1991;37:483-9.

9. McClinton S, Steyn J, Miller ID. Renal malignant fibrous histiocytoma. Br J Urol 1990;65:109-11.

10. Hansen CP, Jensen LM, Holten I. Malignant fibrous histiocytoma of the kidney. Eur Urol 1989;16:395-7.
11. Raghavaiah NV, Mayer RF, Hagitt R, Soloway MS. Malignant fibrous histiocytoma of the kidney. J Urol 1980;123:951-3.

12. Ptochos A, Karydas G, Iosifidis N, Tyrothoulakis E, Papazafiriou G, Kehagias-Koutoufari T. Primary malignant fibrous histiocytoma. Urol Int 1999;63:261-4.

13. Kollias G, Giannopoulos T. Primary malignant fibrous histiocytoma of the kidney: report of a case. J Urol 1987;138:400-1.

14. Thomas JJ, Daniel IB, Arthur FT. Renal malignant fibrous histiocytoma. Urology 1991;37:483-9.

15. Binder SW, Said JW, Shintaku IP, Pinkus GS. A histiocyte-specific marker in the diagnosis of malignant fibrous histiocytoma. Use of monoclonal antibody KP-1 (CD 68). Am J Clin Pathol 1992;97:759-63.

16. Fletcher CDM. Pleomorphic malignant fibrous histiocytoma: fact or fiction? A critical reapprasial based on 159 tumours diagnosed as pleomorphic sarcoma. Am J Surg Pathol 1992;16:213-28.

17. Takashi M, Murase T, Kato K, Koshikawa T, Mitsuya H. Malignant fibrous histiocytoma arising from the renal capsule: Report of case. Urol Int 1987;42:227-30.

18. Schneider JA, Konig H, Hertel E. Malignant fibrous histiocytoma. Br J Urol 1992;69:435-6.

19. Papadopoulos I, Rudolph P. Primary renal malignant fibrous histiocytoma. Urol Int 1999;634:136-8.

20. Scriven RR, Thrasher TV, Smith DC, Stewart SC. Primary renal malignant fibrous histiocytoma: a case report and literature review. J Urol 1984;131:948-9.

21. O'Brien JE, Stout AP. Malignant fibrous xanthomas. Cancer 1964;17:1445-55.

22. Roholl PJM, Kleyne J, Van Unnik JAM. Characterization of tumor cells in malignant fibrous histiocytomas and other soft-tissue tumors, in comparison with malignant histiocytes. 1985;121:269-74.

23. Strauchen JA, Dimitriu-Bona A. Malignant fibrous histiocytoma: expression of monocyte/macrophage differentiation antigens detected with monoclonal antibodies. Am J Pathol 1986;124:303-9.

24. Lopez JI, Angulo JC, Flores N, Toledo JD. Malignant fibrous histiocytoma of the renal capsule and synchronous transitional cell carcinoma of the bladder. Path Res Pract 1996;192:468-71.

25. Leite C, Goodwin JW, Sinkovics JG, Baker LH, Benjamen R. Chemotherapy of malignant fibrous histiocytoma. A Southwest Oncology Group report. Cancer 1977;40:2010-4.

26. Kearny MM, Soule EH, Ivins JC. Malignant fibrous histiocytoma. A retrospective study of 167 cases. Cancer 1980;45:167-17. 